\title{
$\gamma$-Aminobutyric Acid Receptors on Chick Ciliary Ganglion Neurons In Vivo and in Cell Culture
}

\author{
ADRIENNE E. MCEACHERN, JOSEPH F. MARGIOTTA, ${ }^{2}$ AND DARWIN K. BERG ${ }^{3}$
}

Department of Biology, University of California, San Diego, La Jolla, California 92093

\begin{abstract}
In the chick ciliary ganglion, preganglionic terminals maintain cholinergic synapses on the choroid neurons and both cholinergic and electrical synapses on the ciliary neurons. The preganglionic terminals also contain enkephalin- and substance P-like immunoreactivity, suggesting that transmission through the ganglion is more complicated than is indicated by the known synaptic connections. We report here that embryonic chick ciliary ganglion neurons also have $\gamma$ aminobutyric acid (GABA) receptors and that GABA applied to the ganglion can block transmission elicited by preganglionic stimulation.

Studies on the neurons in cell culture indicate that the GABA response is mediated by GABA $_{A}$ receptors: GABA activates a $\mathrm{Cl}^{-}$conductance, and the response can be mimicked by muscimol and blocked by bicuculline or picrotoxin. The GABA receptors are regulated independently from acetylcholine (ACh) receptors on the neurons since the levels of $A C h$ and GABA sensitivity are influenced differently by culture age and by chronic exposure to GABA or elevated $\mathrm{K}^{+}$ concentrations. Application of GABA to intact ciliary ganglia increases the membrane conductance of ganglionic neurons (as in culture), reduces to subthreshold the amplitude of excitatory postsynaptic potentials in the neurons elicited by preganglionic stimulation and completely blocks transmission through the ganglion. A native source of ligand for the receptors in vivo has yet to be identified.
\end{abstract}

Autonomic ganglia have been likened to simple relay stations in which little processing or modification of the signal occurs as it is transmitted from preganglionic to postganglionic ncurons. This once seemed particularly true for the chick ciliary ganglion where no interneurons or synapses between ganglionic neurons have been identified in vivo. The ganglion contains two populations of neurons: choroid neurons that innervate smooth muscle in the choroid layer, and ciliary neurons that innervate striated muscle in the iris and ciliary body. Both populations of neurons are in turn innervated by preganglionic neurons located in the Edinger-Westphal nucleus of

Received November 5, 1984; Revised March 4, 1985 Accepted March 18, 1985

${ }^{1}$ We thank Dr. Nicholas C. Spitzer for comments on the manuscript, Dr. Allen Selverston for use of his equipment, Dannielle Pellegrin for expert technical assistance, and Al Franco, Jr., for help in preparing the figures. Support was provided by National Institutes of Health Grant NS 12601. J. F. $M$. is a National Research Service Fellow.

${ }^{2}$ Present address: Department of Medicine, Division of Pharmacology M013H, University of California, San Diego, La Jolla, CA 92093.

${ }^{3}$ To whom correspondence should be addressed. the midbrain. The preganglionic terminals establish cholinergic synapses on the choroid neurons and maintain both cholinergic and clectrical synapses on the ciliary neurons (Martin and Pilar, 1963; Cantino and Mugnaini, 1975).

The possibility that transmission through the ganglion may be more complex than is indicated by these known synaptic connections arose from the discovery of enkephalin- and substance P-like immunoreactivity in the preganglionic terminals (Erichsen et al., $1982 a, b)$. Recent studies of the neurons in cell culture suggest that the peptides are likely to modulate cholinergic transmission through the ganglion in vivo: substance $P$ enhances desensitization of acetylcholine (ACh) receptors on the neurons, and enkephalin reduces the amplitude of postsynaptic potentials at cholinergic synapses between the neurons in culture and reduces $\mathrm{Ca}^{2+}$ influx in the neurons (Role, 1984; J. F. Margiotta and D. K. Berg, submitted for publication).

Ciliary ganglion neurons are also sensitive to the neurotransmitter $\gamma$-aminobutyric acid (GABA) in vitro (Tuttle, 1983a). The properties of the GABA receptors are largely uncharacterized and their significance for transmission in the ganglion is unknown. We report here that the neurons in dissociated cell culture have GABA receptors with the properties of the $\mathrm{GABA}_{\mathrm{A}}$ subtype (for reviews, see Enna and Gallagher, 1983; Bowery et al., 1984), and that the receptors are regulated independently from the ACh receptors on the neurons. Moreover, in the intact embryonic ganglion the neurons also have GABA receptors, and low concentrations of applied GABA reduce postsynaptic potentials in the neurons and block transmission through the ganglion following preganglionic stimulation. A preliminary account of this work has appeared (McEachern et al., 1984).

\section{Materials and Methods}

Ciliary ganglia from 8-day chick embryos were dissociated and grown in cell culture on a substratum of collagen and lysed fibroblasts as previously described (Nishi and Berg, 1981). Cultures contained 1 to $2 \times 10^{4}$ neurons in 35- $\mathrm{mm}$ plastic dishes and were maintained in medium consisting of Eagle's minimal essential medium (MEM) with $3 \%(\mathrm{v} / \mathrm{v})$ embryonic chick eye extract, $10 \%(\mathrm{v} / \mathrm{v})$ heat-inactivated horse serum, 50 units $/ \mathrm{ml}$ of penicillin, and $50 \mu \mathrm{g} /$ $\mathrm{ml}$ of streptomycin. In some cases cultures were prepared from 18-day embryonic ciliary ganglia using a similar procedure except that the ganglia were dissociated by incubating them for $45 \mathrm{~min}$ at $37^{\circ} \mathrm{C}$ in $1 \mathrm{mg} / \mathrm{ml}$ of collagenase and $5 \mathrm{mg} / \mathrm{ml}$ of dispase rather than trypsin, washing the cells twice by centrifugation in balanced salts to remove the proteases before trituration, and growing them in culture medium containing $5 \%(\mathrm{v} / \mathrm{v})$ embryo extract instead of embryonic eye extract. Cultures receiving medium with embryo extract were treated with $10^{-5} \mathrm{M}$ arabinosylcytosine in the medium for $48 \mathrm{hr}$ between days 3 and 5 to inhibit proliferation of non-neuronal cells. Cultures received fresh medium at 2- to 3-day intervals. Some cultures after the first 2 days received medium supplemented either with $\mathrm{KCl}$ or GABA to final concentrations of $25 \mathrm{~mm} \mathrm{KCl}$ or $100 \mu \mathrm{M}$ GABA.

Intracellular recordings were obtained from the neurons using techniques previously described (O'Lague et al., 1978; Margiotta and Berg, 1982). Cultures were maintained at $37^{\circ} \mathrm{C}$ on the stage of an inverted microscope 
and were continuously perfused with a medium composed of $137 \mathrm{mM} \mathrm{NaCl}$ $5.4 \mathrm{~mm} \mathrm{KCl}, 0.81 \mathrm{~mm} \mathrm{MgSO}_{4}, 0.92 \mathrm{mM} \mathrm{Na}_{2} \mathrm{HPO}_{4}, 0.44 \mathrm{mM} \mathrm{KH}_{2} \mathrm{PO}_{4}, 5.4 \mathrm{~mm}$ $\mathrm{CaCl}_{2}, 5.6 \mathrm{~mm}$ glucose, $2.5 \mathrm{~mm}$ HEPES (pH 7.4), and the essential amino acids and vitamins found in MEM ("HEPES medium"). For experiments in which sensitivity to glutamate was tested and in which reversal potentials were determined (see below), neurons were perfused with a balanced salts solution modified from Dichter and Fischbach (1977) to contain $5.4 \mathrm{~mm} \mathrm{CaCl}$ and 5.0 mM HEPES buffer ( $\mathrm{pH} \mathrm{7.4)} \mathrm{instead} \mathrm{of} \mathrm{bicarbonate} \mathrm{buffer} \mathrm{("recording}$ solution"). Cultures grown in medium supplemented with GABA were washed with six changes of medium lacking GABA over a 1 -hr period of $37^{\circ} \mathrm{C}$, prior to electrophysiological testing. Control cultures acutely exposed to $100 \mu \mathrm{M}$ GABA for $1 \mathrm{hr}$ and washed in this manner showed no decrease in the GABA response when tested subsequently, indicating that the wash procedure was adequate to reverse receptor desensitization.

Neuronal transmitter sensitivities were determined by measuring changes in membrane conductance caused by transmitter being pressure ejected ( 3 to $5 \mathrm{psi}$ for 1 to $3 \mathrm{sec}$ ) from pipettes ( 4 to $6 \mu \mathrm{m}$ tip diameters) positioned 10 to $20 \mu \mathrm{m}$ from the soma (Choi and Fischbach, 1981; Smith et al., 1983). Experiments with $\mathrm{K}^{+}$- and dye-filled micropipettes indicated that the procedure completely immerses the soma in the ejected solution (Choi and Fischbach, 1981; J. F. Margiotta, unpublished observations). Transmitter sensitivities determined in this way are probably the "summed" response of most receptors on the soma. Input conductances were measured using a single intracellular electrode in conjunction with an amplifier and a Wheatstone bridge circuit (W-P. Instruments, model M701): constant current pulses of 0.05 to $0.20 \mathrm{nA}$ amplitude and 50 msec duration were passed through the neuron, and the resulting membrane hyperpolarizations were recorded before and during transmitter exposure. The transmitter-induced conductance was then calculated as the difference between the maximum input conductance measured in the presence of transmitter and the resting input conductance prior to the application of transmitter. Data were accepted only when the neuron had a resting potential more negative than $-45 \mathrm{mV}$ and could fire overshooting action potentials in response to intracellular stimulation, and where the recording electrode was no more than $3 \mathrm{mV}$ out of balance when withdrawn from the neuron. Most cells had resting potentials of -50 to -65 $\mathrm{mV}$ and were routinely held near $-80 \mathrm{mV}$ (holding potentials) with steady hyperpolarizing currents during drug tests. Drug concentrations were usually chosen (e.g., $0.1 \mathrm{~mm} \mathrm{ACh}$ ) that elicited submaximal resporises, and hyperpolarizing holding potentials were applied so that the depolarizations remained within the linear range of the current-voltage relationship for the neurons (Smith et al., 1983). This elımınated the need for corrections due to activation of voltage-dependent ionic conductances which become significant at more depolarized values of the membrane potential. Responses to ACh with this procedure were more than $95 \%$ blocked when $0.025 \mathrm{~mm} d$ tubocurarine was present (J. F. Margiotta, unpublished results).

The reversal potential for the GABA response was usually determined with two intracellular electrodes, one for injecting current and a second for recording membrane voltage changes. Transmitter-induced conductances measured in this way were in close agreement with those obtained in single electrode experiments. In most instances the response could be reversed. In experiments where the $\mathrm{Cl}^{-}$concentration was altered, however, it was necessary to determine the reversal potential by extrapolation. In such cases voltage-dependent channels were blocked by addition of $3 \mu \mathrm{M}$ tetrodotoxin (TTX), $5 \mathrm{~mm}$ tetraethylammonium chloride (TEA), and $10 \mathrm{~mm} \mathrm{CoCl}_{2}$ to the recording solution. $\mathrm{Cl}^{-}$concentrations were altered by substituting isethionate, and $\mathrm{K}^{+}$changes were compensated by changing the $\mathrm{Na}^{+}$concentration.

To determine whether functional $\mathrm{GABA}_{\mathrm{B}}$ receptors were present on the neurons, the effects of GABA on the $\mathrm{Ca}^{2+}$ component of the neuronal action potential were examined. In these cases it was necessary to enhance the duration of the $\mathrm{Ca}^{2+}$ component by decreasing $\mathrm{K}^{+}$currents. This was achieved by adding 5 or $10 \mathrm{mM}$ TEA to the HEPES medium (similar results were obtained with both concentrations) and by using either $1 \mathrm{M}$ potassium acetate or $1 \mathrm{M} \mathrm{CsCl}$ as the electrolyte in the recording electrode (Bader et al., 1982; J. F. Margiotta, unpublished observations). Potassium acetate electrodes were used in most cases because it has been reported that loading dorsal root ganglion neurons with $\mathrm{Cs}^{+}$may block the $\mathrm{GABA}_{\mathrm{B}}$ response (Désarmenien et al., 1984). In addition, GABA effects on $\mathrm{Cl}^{-}$ conductance in these experiments were blocked by $250 \mu \mathrm{M}$ picrotoxin in the HEPES medium. In other systems $\mathrm{GABA}_{\mathrm{B}}$ receptors appear to be insensitive to picrotoxin (Dunlap and Fischbach, 1978; Bowery et al., 1981).

For experiments on intact preparations, ciliary ganglia from 15- to 16-day chick embryos were dissected with pre- and postganglionic nerve stumps attached. The ganglion was mounted in the center well of a three-chamber dish such that the nerve stumps extended into adjacent wells and the chambers could be electrically isolated by Vaseline seals. Ag-AgCl wires were used to stimulate the preganglionic nerve stump across the seal at a frequency of $0.5 \mathrm{~Hz}$, using current pulses of 0.2 msec duration and 4 to $6 \mathrm{~V}$ amplitude, applied through a stimulus isolation unit. A second set of $\mathrm{Ag}-\mathrm{AgCl}$ wires was used to record extracellularly the biphasic compound action potential in the postganglionic nerve stump that was triggered by synaptic transmission through the ganglion. The stimulus paradigm was chosen to elicit the maximum response with little or no rundown. The peak-to-peak amplitude of the compound action potential was measured from photographs of oscilloscope traces or directly from the screen. Drug effects were evaluated by measuring the change they produced in the peak-to-peak amplitude. Drugs were applied by adding them to the HEPES medium that continuously perfused the ganglion at room temperature.

Intracellular recordings from neurons in intact ganglia were made using the techniques described for dissociated cell culture. For these experiments, whole ganglia from 16-day chick embryos were pinned to a thin layer of Sylgard resin (Dow Corning). Preganglionic nerve stumps were stimulated with $\mathrm{Ag}-\mathrm{AgCl}$ wires while recording intracellularly from the neurons to observe evoked excitatory postsynaptic potentials (EPSPs). Drugs in these cases were applied either directly in the perfusing solution or from a pipette (4 to 6 $\mu \mathrm{m}$ tip diameter) positioned immediately above the ganglion.

Quantitative results are expressed as the mean \pm SEM for the number of determinations indicated in parentheses.

Culture media components were obtained from Grand Island Biological Co. GABA, ACh, $\beta$-alanine, glycine, taurine, glutamate, muscimol, picrotoxin, (+)-bicuculline, HEPES, and TEA were obtained from Sigma Chemical Co., collagenase and dispase (grade II) were obtained from Boehringer Mannheim; and TTX was obtained from Calbiochem.

\section{Results}

GABA sensitivity. Brief application of GABA to ciliary ganglion neurons grown in dissociated cell culture produced a depolarization and an increase in membrane conductance (Fig. 1A). Prolonged application of GABA resulted in a desensitization of the response. The concentration dependence of the GABA rcsponsc was determined by measuring the maximum change in membrane conductance produced by various concentrations of GABA. Half-maximal responses were obtained at about $9 \mu \mathrm{M}$ GABA (Fig. 2). GABA at 50 $\mu \mathrm{M}$ elicited a near-maximal response with a conductance change of $22.0 \pm 3.2 \mathrm{nS}$ ( $n=46$ neurons). These measurements were carried out on neurons 4 to 6 days in culture. All ciliary ganglion neurons were sensitive to GABA prior to day 6 in culture $(n=226)$, whereas $20 \%$ were insensitive to GABA between days 7 and 14 in culture $(n=104)$.

Pharmacology. Muscimol, a GABA agonist, induced similar membrane conductance changes in the neurons (Fig. 1B). The mean response to $50 \mu \mathrm{M}$ muscimol $(16.7 \pm 6.0 \mathrm{nS}, n=11)$ was not significantly different from that obtained tor $50 \mu \mathrm{M}$ GABA. The GABA antagonists, bicuculline and picrotoxin, each at $100 \mu \mathrm{M}$, blocked the response to $50 \mu \mathrm{M}$ GABA by $97.4 \pm 0.9 \%(n=10)$ and $97.8 \pm$ $1.2 \%(n=5)$, respectively. Examples are shown in Figure 3 . Ciliary ganglion neurons also displayed increases in membrane conductance when challenged with $1 \mathrm{~mm}$ glycine $(n=10), 1 \mathrm{~mm} \beta$-alanine $(n=3)$, or $1 \mathrm{~mm}$ taurine $(n=4)$, but the responses were at least 10 -fold smaller than those elicited by $50 \mu \mathrm{M}$ GABA. No responses were observed when $100 \mu \mathrm{M}$ glutamate $(n=3)$ was applied to the neurons.
A

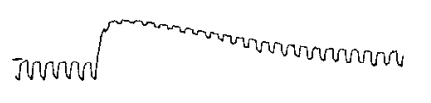

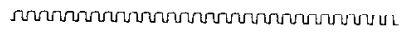

B

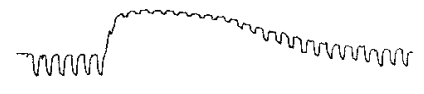

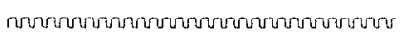

Figure 1. Neuronal response to GABA and muscimol. A ciliary ganglion neuron at 4 days in culture was tested for responses to $50 \mu \mathrm{M}$ GABA $(A)$ and to $50 \mu \mathrm{M}$ muscimol $(B)$. Top trace, membrane potential; bottom trace, injected current pulses. Holding potentials were $-75 \mathrm{mV}(A)$ and $-73 \mathrm{mV}$ $(B)$; resting potential was $-68 \mathrm{mV}$. Calibration bars : horizontal, $1 \mathrm{sec}$; vertical, $20 \mathrm{mV}, 0.2 \mathrm{nA}$. Horizontal bar, duration of drug application. 


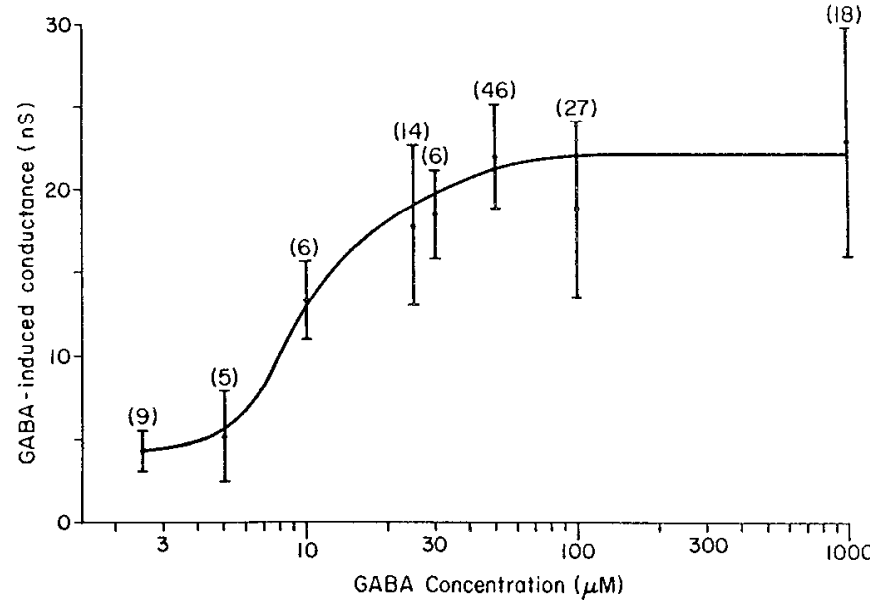

Figure 2. Concentration dependence of GABA response. The indicated concentrations of GABA were applied to neurons and the conductance increase was determined. The values represent the mean \pm SEM for responses from the number of neurons indicated in parentheses. Data were compiled from 21 cultures taken from 14 separate platings. Cultures were 4 to 6 days old
A

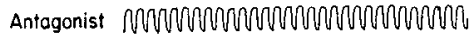

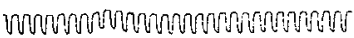

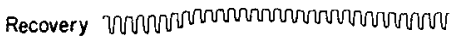

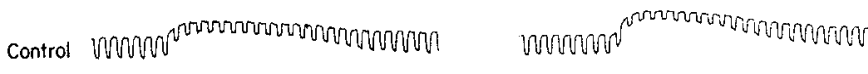

$\mathrm{GABA}_{\mathrm{B}}$ receptors with age in culture that, when activated, decrease the $\mathrm{Ca}^{2+}$ component of the action potential (Dunlap, 1984). We tested ciliary ganglion neurons for $\mathrm{GABA}_{B}$ receptors by examining the effects of GABA on the $\mathrm{Ca}^{2+}$ component of the neuronal action potential. Ciliary ganglion neurons in cell culture have a mixed action potential consisting of a fast $\mathrm{Na}^{+}$component and a delayed $\mathrm{Ca}^{2+}$ component (Bader et al., 1982). Addition of 5 to $10 \mathrm{~mm}$ TEA to the bathing solution inhibits $\mathrm{K}^{+}$currents and prolongs the $\mathrm{Ca}^{2+}$ component. This can result in a shoulder on the action potential of up to $500 \mathrm{msec}^{3} 3.8 \mathrm{~mm} \mathrm{Co}^{2+}$ or $2 \mathrm{mM} \mathrm{Cd}^{2+}$ in the bathing solution blocks the appearance of the shoulder as expected for potential changes dependent on $\mathrm{Ca}^{2+}$ currents (Bader et al., 1982; A. E. McEachern and J. F. Margiotta, unpublished results). In the present studies, 250 $\mu \mathrm{M}$ picrotoxin was also added to the bathing solution to block GABAinduced changes in $\mathrm{Cl}^{-}$conductance that might obscure an effect on $\mathrm{Ca}^{2+}$ currents. For these experiments, dissociated cell cultures were prepared both from 8-day embryonic ganglia and tested 4 to 30 days later, and from 18-day embryonic ganglia and tested 5 to 12 days later. This range was chosen to reveal the possible appearance of $\mathrm{GABA}_{\mathrm{B}}$ receptors at late times in development. Out of a total of 43 neurons examined ( 13 cultures, 8 separate platings), no cases were found in which the duration of the action potential was altered when GABA was applied to the neurons (data not shown).

Regulation. Comparing GABA and ACh sensitivities at different times in culture indicates that the neurons regulate the two kinds of receptors differently. Mean ACh sensitivities increase 9-fold between days 1 and 3 in culture and then are maintained until at least day 7 with the growth conditions used here (Smith et al., 1983). In contrast, mean sensitivities to 50 to $100 \mu \mathrm{M}$ GABA dccline 2-fold over this time period ( $47 \pm 10 n S, n=13$ at day 1 versus $19 \pm 4 n S, n=44$ at days 6 and 7 ), although there is considerable variation in the response among neurons. Additional evidence that GABA and ACh sensitivities are regulated differently comes from neurons exposed to culture medium containing $25 \mathrm{mM} \mathrm{K}^{+}$for 3 days. After rinsing the neurons to remove the extra $\mathrm{K}^{+}$, they display 3 - to 4 -fold lower ACh responses than do neurons grown in normal medium, but they show no difference in their GABA responses (Fig. 5).

Figure 3. Antagonists for the GABA response. Each vertical column represents recordings from a single neuron while challenging it with $50 \mu \mathrm{M}$ GABA (duration indicated by horizontal bar). Control, response to GABA alone, prior to application of antagonist. Antagonist, response to GABA either when $100 \mu \mathrm{m}$ bicuculline was bath applied to the neuron and co-applied with GABA in the pipette $(A)$ or when $100 \mu \mathrm{M}$ picrotoxin was co-applied with GABA in the pipette (but not bath applied) $(B)$. Recovery, response to GABA alone, 2 to $5 \mathrm{~min}$ after removal of the antagonist. Resting potentials were $-61 \mathrm{mV}(A)$ and $-60 \mathrm{mV}(B)$; cultures were $6(A)$ and $7(B)$ days old. Calibration bars: horizontal, $1 \mathrm{sec}$; vertical, $20 \mathrm{mV}$.

Ionic basis. The ionic basis of the GABA response was examined by determining its reversal potential. Using electrodes containing 1 $M$ potassium acetate to stimulate and record from the neurons, we obtained a reversal potential of $-51 \pm 2 \mathrm{mV}(n=5)$ (Fig. 4). The reversal potential obtained with $1 \mathrm{M} \mathrm{KCl}$ electrodes was shifted to $-20 \pm 3 \mathrm{mV}(n=5)$, suggesting that $\mathrm{Cl}^{-}$ions mediate the GABA response. This was confirmed by using a potassium acetate electrode while altering the concentration of $\mathrm{Cl}^{-}$in the bathing solution to determine the effect on the reversal potential (Fig. 4). Low Cl${ }^{-}$ concentrations $(43 \mathrm{mM})$ resulted in a mean reversal potential of -17 $\pm 2 \mathrm{mV}(n=6)$. Since changes in extracellular $\mathrm{Cl}^{-}$concentrations are known to cause significant $\mathrm{Cl}^{-}$shifts across the cell membrane, measurements in these cases were carried out within the first 2 min following the bath change (Barker and Ransom, 1978; Bixby and Spitzer, 1982). $\mathrm{Na}^{+}$appears not to be involved in the GABA response, since replacing it with Tris, $\mathrm{pH} 7.4(150 \mathrm{~mm})$, resulted in a mean reversal potential of $-48 \pm 1 \mathrm{mV}(n=3)$. Similarly, low external $\mathrm{K}^{+}$concentrations ( $2 \mathrm{~mm}$ instead of the usual $5.3 \mathrm{~mm}$ ) gave rise to a mean reversal potential of $-50 \pm 1 \mathrm{mV}(n=3)$, and high external $\mathrm{K}^{+}(12 \mathrm{mM})$ resulted in a reversal potential of $-50 \pm 2 \mathrm{mV}$ $(n=3)$. Neither of these are significantly different from controls.

Chick dorsal root ganglion neurons have been shown to acquire
A
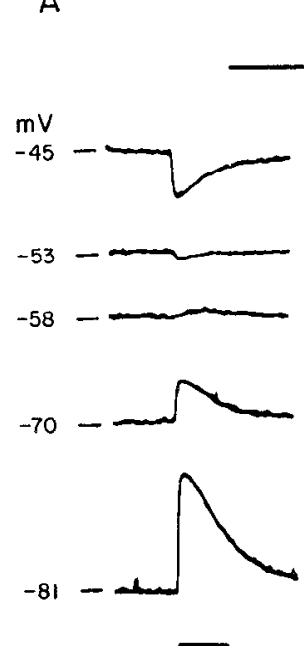

$-81$

$\mathrm{B}$

Figure 4. Reversal potential for the GABA response. A, Membrane potential changes observed at various holding potentials (indicated by numbers by horizontal bar) in recording solution. Calibration bars: horizontal, $2 \mathrm{sec}$; vertical, $10 \mathrm{mV}$. $B$, Reversal potential of $-54 \mathrm{mV}$ for the neuron in $A()$ and reversal potential of $-15 \mathrm{mV}$ for a neuron in recording solution in which the $\mathrm{Cl}^{-}$concentration was reduced to $43 \mathrm{~mm}(O)$. The differences in slope for the two determinations arise from differences in membrane resistance and GABA-induced conductance changes for the two neurons; considerable variation in the latter is seen among neurons in culture (see the tcxt). The cultures were 6 (control) and $5\left(\mathrm{Cl}^{-}\right.$shift) days old. on the left) when $100 \mu \mathrm{M}$ GABA was applied to a neuron (duration indicated 


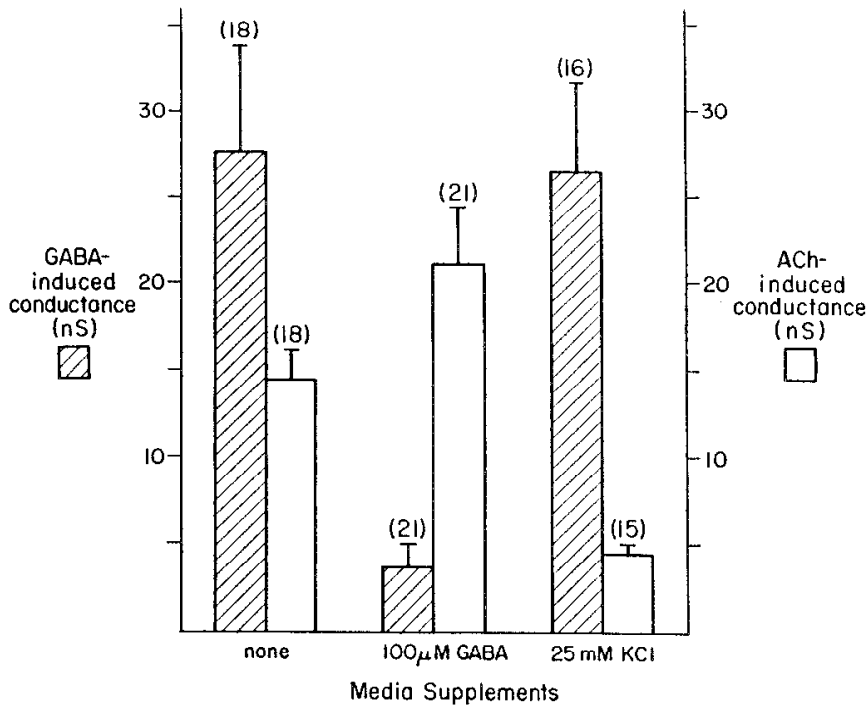

Figure 5. Independent regulation of GABA and ACh responses. Neurons were grown with the indicated supplements to the culture medium as described under "Materials and Methods" and then were tested in HEPES medium for responses to $50 \mu \mathrm{M}$ GABA and $100 \mu \mathrm{M} \mathrm{ACh}$ after thorough rinsing to remove the supplements.

Still another difference in regulation can be seen when neurons are chronically exposed to GABA in the culture medium. After 3 days in $100 \mu \mathrm{M}$ GABA followed by extensive rinsing, the neurons displayed a 7- to 8-fold reduction in GABA sensitivity compared to control neurons. In contrast, the regimen had no effect on neuronal ACh sensitivities (Fig. 5). The reduction in GABA sensitivity by the chronic exposure is unlikely to represent persistent desensitization of GABA receptors since acute exposure of the neurons (1 hr) to $100 \mu \mathrm{M}$ GABA followed by similar rinsing revealed no reduction in GABA sensitivity.

Whole ganglia. Intracellular recordings from neurons in whole ciliary ganglia of 16-day embryos demonstrate that they have functional GABA receptors. Application of $500 \mu \mathrm{M}$ GABA to a ganglion from a pipette produced a conductance increase in the neurons similar to that observed in cell culture (Fig. 6). Similar results were obtained in nine other experiments in which GABA was applied either in the bath at $100 \mu \mathrm{M}$ or from a pipette at $500 \mu \mathrm{M}$.

The effects of GABA on synaptic transmission through the whole ganglion were tested by applying the substance to intact ganglia while using extracellular electrodes to stimulate the preganglionic nerve slump and record the induced biphasic compound action potential in postganglionic ciliary nerve stumps. GABA at $15 \mu \mathrm{M}$ completely blocked transmission through the ganglion in this assay. Half-maximal blockade was achieved at about $3 \mu \mathrm{M}$ GABA (Fig. 7). Incubation of the ganglion in $50 \mu \mathrm{M}$ picrotoxin prior to and during exposure to 10 to $15 \mu \mathrm{M}$ GABA resulted in a $38.3 \pm 0.9 \%(n=3)$ protection against the GABA blockade. Similar protection was observed when $20 \mu \mathrm{M}(+)$-bicuculline was tested against $10 \mu \mathrm{M} \mathrm{GABA}$.

GABA applied to the ganglion while stimulating the preganglionic nerve sufficiently reduced the EPSP amplitude recorded intracellularly in ganglionic neurons to prevent them from firing action potentials (Fig. 8).

\section{Discussion}

Two major types of GABA receptors have been distinguished physiologically on vertebrate neurons: $G A B A_{A}$ and $G A B A_{B}$ (for reviews, see Enna and Gallagher, 1983; Bowery et al., 1984). Embryonic chick ciliary ganglion neurons have receptors of the $G A B A_{A}$ subtype in cell culture. The receptors respond to both GABA and muscimol as agonists, they are blocked by picrotoxin and bicuculline, and they increase $\mathrm{Cl}^{-}$conductances when aclivated. GABA receptors are thought to inhibit voltage-dependent $\mathrm{Ca}^{2+}$ conduct- ances and/or increase $\mathrm{K}^{+}$conductances (Désarmenien et al., 1984; Newberry and Nicoll, 1984a, b). Ciliary ganglion neurons lack detectable $\mathrm{GABA}_{\mathrm{B}}$ receptors as assayed by monitoring the $\mathrm{Ca}^{2+}$ component of the action potential when cells are challenged with GABA, and by determining the GABA reversal potential in different external concentrations of $\mathrm{K}^{+}$.

GABA receptors are regulated differently from $A C h$ receptors on chick ciliary ganglion neurons in culture. Chronic exposure to GABA causes a decrease in the GABA response without affecting the ACh

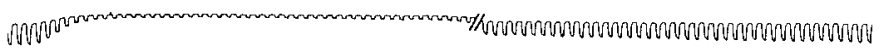

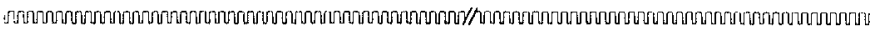

Figure 6. GABA response of a ciliary ganglion neuron in situ. GABA $(500$ $\mu \mathrm{M}$ ) was applied from a pipette (horizontal bar below the record) to a 16-day embryonic ciliary ganglion while recording the change in voltage and conductance with an intracellular electrode. GABA-induced conductance increase, $40 \mathrm{nS}$; resting potential, $-57 \mathrm{mV}$. Calibration bars: horizontal, $1 \mathrm{sec}$; vertical, $20 \mathrm{mV}$ (top trace), $0.2 \mathrm{nA}$ (bottom trace). The break in the record represents $8 \mathrm{sec}$. Full recovery was achieved.

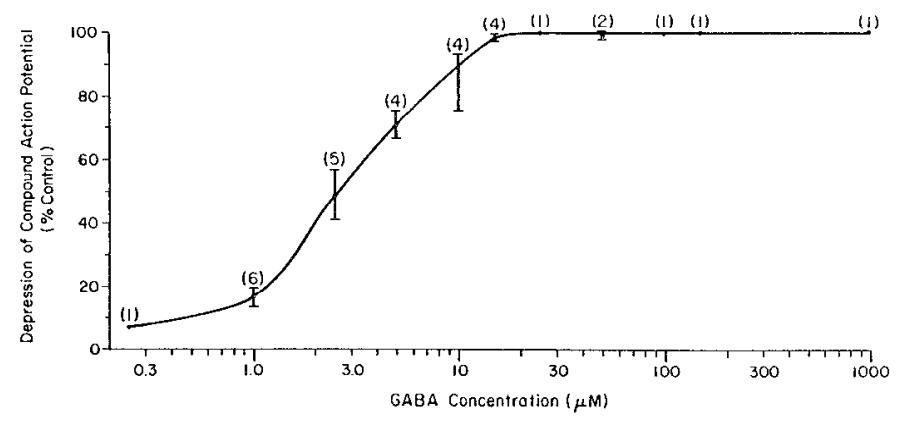

Figure 7. GABA concentration dependence for blockade of transmission through the ciliary ganglion. I ransmission through the ciliary ganglion was monitored by stimulating the preganglionic nerve stump of 15- to 16-day embryonic ganglia with $\mathrm{Ag}-\mathrm{AgCl}$ wires while extracellularly recording the biphasic compound action potential elicited in the postganglionic ciliary nerve stumps. The indicated concentrations of GABA were bath applied to the ganglia and their effects on transmission were evaluated by measuring the change in the peak-to-peak amplitude of the compound action potential. Data are compiled from 12 ganglia, two to three determinations/ganglion.

A

B

$\mathrm{C}$
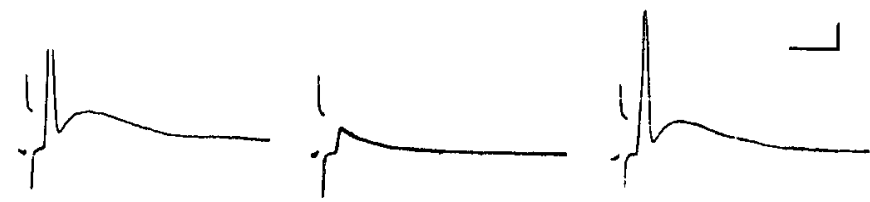

Figure 8. Decrease of EPSP amplitude in situ by GABA. Transmission through a 16-day embryonic ganglion was elicited by preganglionic stimulation as described in Figure 7 while postsynaptic responses were monitored with an intracellular electrode. A, Membrane potential response of a ganglionic neuron to preganglionic stimulation in the absence of GABA. An action potential was triggered on the steep rising phase of the evoked EPSP. B. Response of neuron to preganglionic stimulation during application of 500 $\mu \mathrm{M}$ GABA from a pipette above the ganglion. GABA reduced the EPSP amplitude to below threshold for firing an action potential in the neuron. Hyperpolarizing the membrane potential during the test led to an increase in the armplitude of the remaining response (trials not shown), confirming that it represented a chemical EPSP though attenuated by GABA. C, Recovery of EPSP amplitude to threshold for firing an action potential after extensive washing to remove applied GABA. Resting potential, $-57 \mathrm{mV}$. Calibration bars: horizontal, $20 \mathrm{msec}$; vertical, $20 \mathrm{mV}$. 
response. Growing the neurons in elevated $\mathrm{K}^{+}$concentrations has the opposite effect. The developmental time courses for the responses are also different: $A C h$ sensitivity increases at a time in culture when GABA sensitivity remains constant or decreases. A similar conclusion was reached on the independent regulation of GABA and ACh receptors on ciliary ganglion neurons in a brief account of other experiments (Tuttle, 1983a). In some cases ACh sensitivity of ciliary ganglion neurons has been found to decline at early times in culture (Crean et al., 1982; Tuttle, 1983b); these results, which contrast with those reported here and previously (Smith et al., 1983), were obtained with neurons from older ganglia grown under conditions different from those used here, and they were assayed with focal iontophoretic application of ACh rather than with puffer application. At least one of these differences, i.e., culture substratum, is known to alter levels of ACh sensitivity associated with the neurons in a manner that would help reconcile these differences (Tuttle, 1983b). With respect to differential regulation of receptors it should also be noted that physiological studies of the type described here do not exclude the possibility that the differences observed reflect differences in receptor function rather than receptor number since the assays do not measure number directly. Nonetheless, it is clear that the GABA response is subject to its own set of controls.

$\mathrm{G} \wedge \mathrm{B} \wedge$ receptors are present on embryonic ciliary ganglion neurons in vivo since application of GABA to the neurons increases their membrane conductance. GABA applied to the ganglion can also depress the amplitude of EPSPs elicited in the neurons by preganglionic stimulation to values below threshold for triggering action potentials in the neurons. At 10 to $15 \mu \mathrm{M}$, GABA completely blocks transmission through the ganglion. Since activity was monitored only in ciliary nerves during the blocking experiments, it cannot be stated with certainty that transmission is blocked for both ciliary and choroid neurons. Both types of neurons can be inferred to have $\mathrm{GABA}_{\mathrm{A}}$ receptors in cell culture, however, since every neuron tested in the first week was sensitive to GABA under conditions where both neuronal populations are known to survive in culture (Nishi and Berg, 1981). These results are consistent with GABA blocking transmission through the ganglion by shunting the postsynaptic current elicited by $A C h$. It should be noted that we cannot exclude the possibility that GABA also has a presynaptic effect in the ganglion, depressing transmitter release. Both pre- and postsynaptic inhibitory effects have been reported for GABA on transmission in the myenteric plexus (Cherubini and North, 1984a, b) and in sympathetic ganglia (Adams and Brown, 1975; Kato et al., 1978). The concentration of GABA required to achieve half-maximal blockade of transmission through the ciliary ganglion $(3 \mu \mathrm{M})$ is lower than that required to achieve a half-maximal response in cell culture $(9 \mu \mathrm{M})$, but this difference may well reflect the fact that blockade of transmission depends on reducing the EPSP amplitude to subthreshold values rather than on activating enough GABA receptors to elicit a halfmaximal increase in conductance. A previous report (Obata et al., 1978 ) indicated that bath-applied GABA (1 to $\left.50 \times 10^{-6} \mathrm{M}\right)$ carl facilitate synaptic transmission between ciliary ganglion explants and skeletal myotubes in culture; the cellular basis for that GABA effect remains unknown.

GABA receptors have been found on a wide variety of autonomic and sensory neurons (for reviews, see Nistri and Constanti, 1979; Enna and Gallagher, 1983). Although GABA has been extensively documented to serve as an inhibitory neurotransmitter in invertebrates and in the vertebrate central nervous system (for review, see Roberts et al., 1976), its role in the vertebrate peripheral nervous system is not clear. Cells of the myenteric plexus contain GABA and glutamic acid decarboxylase (GAD) and accumulate GABA (Jessen et al., 1979), have GABA receptors (Cherubini and North, 1984a, b), and release GABA upon stimulation (Taniyama et al., 1982). GABA, GAD-, and GABA transaminase-like immunoreactivity and $\mathrm{Na}^{+}$-dependent GABA uptake have been demonstrated in bovine adrenal chromaffin cells (Kataoka et al., 1984), and GABA has been reported to be in autonomic and sensory ganglia (Bertilsson et al., 1976). An in vivo role for GABA in these systems, however, has yet to be demonstrated. It has been suggested for sensory neurons that the GABA receptors mediate primary afferent depolarization (Levy, 1977). Perhaps GABA receptors on autonomic neurons also serve a function external to the ganglion such as mediating presynaptic inhibition at axon terminals. Alternatively, they may normally respond to blood-borne GABA (Kato et al., 1980), to GABA from yet undiscovered ganglionic sources, or to some other ligand in ganglia that activates the same receptor. Identifying a ligand source in vivo for the receptors would be very informative for evaluating their significance in normal ganglionic function. Clearly GABA receptors have the potential for playing a major role in modulating transmission through the chick ciliary ganglion.

\section{References}

Adams, P. R., and D. A. Brown (1975) Actions of $\gamma$-aminobutyric acid on sympathetic ganglion cells. J. Physiol. (Lond.) 250: 85-120.

Bader, C. R., D. Bertrand, and A. C. Kato (1982) Chick ciliary ganglion in dissociated cell culture. II. Electrophysiological properties. Dev. Biol. 94: 131-141.

Barker, J. L., and B. R. Ransom (1978) Amino acid pharmacology of mammalian central neurones grown in tissue culture. J. Physiol. (Lond.) 280: 331-354.

Bertilsson, L., A. Suria, and E. Costa (1976) $\gamma$-aminobutyric acid in rat superior cervical ganglion. Science 260: 540-541.

Bixby, J. L., and N. C. Spitzer (1982) The appearance and development of chemosensitivity in Rohon-Beard neurones of Xenopus spinal cord. J. Physiol. (Lond.) 330: 513-536.

Bowery, N. G., A. Doble, D. R. Hill, A. L. Hudson, J. S. Shaw, M. J. Turnbull, and R. Warrington (1981) Bicuculline-insensitive GABA receptors on peripheral autonomic nerve terminals. Eur. J. Pharmacol. 71: 53-70.

Bowery, N. G., D. R. Hill, A. L. Hudson, G. W. Price, M. J. Turnbull, and G. $P$. Wilkin (1984) Heterogeneity of mammalian GABA receptors. In Actions and Interactions of GABA and Benzodiazepines, N. G. Bowery, ed., pp. 81-108, Raven Press, New York.

Cantino, D., and E. Mugnaini (1975) The structural basis for electrotonic coupling in the avian ciliary ganglion. A study with thin sectioning and freeze-fracturing. J. Neurocytol. 4: 505-536.

Cherubini, E., and R. A. North (1984a) Actions of $\gamma$-aminobutyric acid on neurones of guinea-pig myenteric plexus. Br. J. Pharmacol. 82: 93-100.

Cherubini, E., and R. A. North (1984b) Inhibition of calcium spikes and transmitter release by $\gamma$-aminobutyric acid in the guinea-pig myenteric plexus. Br. J. Pharmacol. 82: 101-105.

Choi, D. W. and G. D. Fischbach (1981) GABA conductance of chick spinal cord and dorsal root ganglion neurons in cell culture. J. Neurophysiol. 45: 605-620

Crean, G., G. Pilar, J. B. Tuttle, and K. Vaca (1982) Enhanced chemosensi tivity of chick parasympathetic neurones in co-culture with myotubes. J. Physiol. (Lond.) 331: 87-104.

Désarmenien, M., P. Feltz, G. Occhipinti, F. Santangelo, and R. Schlichter (1984) Coexistence of $G_{A B A}$ and $G A B A_{B}$ receptors on $A \delta$ and $C$ primary afferents. Br. J. Pharmacol. 81: 327-333.

Dichter, M. A., and G. D. Fischbach (1977) The action potential of chick dorsal root ganglion neurones maintained in cell culture. J. Physiol. (Lond.) 267: 281-298.

Dunlap, K. (1984) Functional and pharmacological differences between two types of GABA receptor on embryonic chick sensory neurons. Neurosci. Lett. 47: 265-270.

Dunlap, K., and G. D. Fischbach (1978) Neurotransmitters decrease the calcium component of sensory neurone action potentials. Nature 276. 837-839.

Enna, S. J., and J. P. Gallagher (1983) Biochemical and electrophysiological characteristics of mammalian GABA receptors. Int. Rev. Neurobiol. 24: 181-212.

Erichsen, J. T., A. Reiner, and H. J. Karten (1982a) Co-occurrence of substance P-like and leu-enkephalin-like immunoreactivities in neurones and fibres of avian nervous system. Nature 295: 407-410.

Erichscn, J. T., H. J. Karten, W. D. Eldred, and N. C. Brecha (1982b) Localization of substance $P$-like and enkephalin-like immunoreactivity within preganglionic terminals of the avian ciliary ganglion: Light and electron Iricruscopy. J. Neurosci. 2: 994-1003.

Jessen, K. R., R. Mirsky, M. E. Dennison, and G. Burnstock (1979) GABA 
may be a neurotransmitter in the vertebrate peripheral nervous system. Nature 281: $71-74$

Kataoka, Y., Y. Gutman, A. Guidotti, P. Panula, J. Wroblewski, D. CosenzaMurphy, J. Y. Wu, and E. Costa (1984) Intrinsic GABAergic system of adrenal chromaffin cells. Proc. Natl. Acad. Sci. U. S. A. 81: 3218-3222.

Kato, E., K. Kuba, and K. Koketsu (1978) Presynaptic inhibition by $\gamma$ aminobutyric acid in bullfrog sympathetic ganglion cells. Rrain Res. 153 : 398-402.

Kato, E., K. Morita, K. Kuba, S. Yamada, T. Kuhara, T. Shinka, and I. Matsumoto (1980) Does $\gamma$-aminobutyric acid in blood control transmitter release in bullfrog sympathetic ganglia? Brain Res. 195: 208-214.

Levy, R. A. (1977) The role of GABA in primary afferent depolarization. Prog. Neurobiol. 9: 211-267

Margiotta, J. F., and D. K. Berg (1982) Functional synapses are established between ciliary ganglion neurones in dissociated cell culture. Nature 296: $152-154$.

Martin, A. R., and G. Pilar (1963) Dual mode of synaptic transmission in the avian ciliary ganglion. J. Physiol. (Lond.) 168: 443-463.

McEachern, A. E., J. F. Margiotta, and D. K. Berg (1984) GABA receptors on chick ciliary ganglion neurons. Soc. Neurosci. Abstr. 10: 646.

Newberry, N. R., and R. A. Nicoll (1984a) A bicuculline-resistant inhibitory postsynaptic potential in rat hippocampal pyramidal cells in vitro. J. Physiol. (Lond.) 348: 239-254.

Newberry, N. R., and R. A. Nicoll (1984b) Direct hyperpolarizing action of baclofen on hippocampal pyramidal cells. Nature 308: 450-452.

Nishi, R., and D. K. Berg (1981) Two components from eye tissue that differentially stimulate the growth and development of ciliary ganglion neurons in cell culture. J. Neurosci. 1: 505-513.

Nistri, A., and A. Constanti (1979) Pharmacological characterization of different types of GABA and glutamate receptors in vertebrates and invertebrates. Prog. Neurobiol. 13: 117-235.

Obata, K., M. Oide, and H. Tanaka (1978) Excitatory and inhibitory actions of GABA and glycine on embryonic chick spinal neurons in culture. Brain Res. 144: 179-184

O'Lague, P. H., D. D. Potter, and E. J. Furshpan (1978) Studies on rat sympathetic neurons developing in cell culture. I. Growth characteristics and electrophysiological properties. Dev. Biol. 67: 384-403.

Roberts, E. E., T. N. Chase, and D. B. Tower (1976) GABA in Nervous System Function, Raven Press, New York.

Role, L. W. (1984) Substance P modulation of acetylcholine-induced currents in embryonic chicken sympathetic and ciliary ganglion neurons. Proc. Natl. Acad. Sci. U. S. A. 81: 2924-2928.

Smith, M. A., J. F. Margiotta, and D. K. Berg (1983) Differential regulation of acetylcholine sensitivity and $\alpha$-bungarotoxin-binding sites on ciliary ganglion neurons in cell culture. J. Neurosci. 3: 2395-2402.

Taniyama, K., M. Kusunoki, N. Saito, and C. Tanaka (1982) Release of $\gamma$ aminobutyric acid from cat colon. Science 217: 1038-1040.

Tuttle, J. B. (1983a) Regulation of chemosensitivity in cultured chick ciliary ganglion neurons. Soc. Neurosci. Abstr. 9: 845.

Tuttle, J. B. (1983b) Interactions with membrane remnants of target myotubes maintains transmitter sensitivity of cultured neurons. Science 220: $977-$ 979 . 